\title{
Archaeometric investigations of medieval stained glass panels from Grodziec in Poland
}

\author{
Dariusz Wilk $^{1 \star}$, Marta Kamińska ${ }^{2}$, Małgorzata Walczak $^{2}$, Ewa Bulska ${ }^{1}$ \\ 1 Faculty of Chemistry, Biological and Chemical Research Centre, University of Warsaw, Żwirki \\ i Wigury 101, 02-089 Warsaw, Poland \\ 2 Faculty of Conservation and Restoration of Works of Art, Jan Matejko Academy of Fine Arts in \\ Kraków, Pl. Matejki 13, 31-157 Kraków, Poland \\ * Corresponding author: dariusz.wilk@uj.edu.pl
}

\begin{abstract}
Two stained glass panels of Austrian origin from the $15^{\text {th }}$ century were formerly placed in Grodziec castle in Poland and nowadays they belong to the collection of the National Museum in Wrocław. The main aim of this work was to evaluate the chemical composition of glass from medieval and modern parts of the panels. Elemental composition of bulk glass and external layers of glass samples was determined with the use of SEM-EDX and LA-ICP-MS methods. Morphology of the deteriorated glass was investigated through SEM-BSE images of the cross-sections. Moreover, the longitudinal concentration profiles were determined by LA-ICP-MS measurements.

Results show that stained glass panels reveal characteristic elemental composition of wood ash glass produced from 1000 to $1400 \mathrm{AD}$. Almost equal proportions of potassium and calcium oxides indicate that high quality of beech wood was applied by manufacturers. Main and minor elements content was common for almost all investigated glass samples, which suggests that manufacturers follow strictly the assumed recipe during panels production. Differences in elemental composition detected for minor or trace elements were connected to colour additives. Stained glass samples from glazing exhibit composition of typical modern glass. Considerable differences between the composition of healthy bulk glass and the deteriorated surface of glass were detected though SEM-BSE images and LA-ICP-MS longitudinal concentration profiles. High concentrations of lead, copper and iron were noticed in external layers of glass samples, which can be explained by the presence of decorative paint layers and drawings.
\end{abstract}

Keywords: stained glass, wood ash glass, elemental composition, SEM-EDX, LA-ICP-MS

\section{Introduction}

Stained glass windows were one of the most important and precious features of medieval architecture and were used predominantly in churches, only rarely in private or public buildings. Technology and raw materials used in the manufacturing of glass have changed during ages. Glass is usually formed by melting a mixture of specific materials. It consists chiefly of three components: the network former, which in the case of silicate glasses is silicon dioxide $\mathrm{SiO}_{2}$, the alkaline ingredient working as a modifier, and the 
stabilizing agent. The melting temperature of pure silica, which is $1610^{\circ} \mathrm{C}$, makes the production of silicate glass complicated and expensive [1]. To obtain a glass easier to produce, it is necessary to add network modifiers and stabilizers. $\mathrm{SiO}_{2}$ was introduced in ancient glass generally as sea sand. According to Davison [2], network modifiers, called fluxants (usually alkali: $\mathrm{Na}, \mathrm{K}$ ), were added to the batch as natron or plants ashes in order to lower the melting temperature of the vitrifier. For glass becomes non-resistant to water after the addition of alkalis, it must be stabilized by the addition of alkaline earths (Mg, Ca). Seashells or other carbonic fragments occurring in marine sand were the sources of lime.

Three major glass types were used in the medieval period [3-5]. Soda ash glass was produced from about $1500 \mathrm{BC}$ to the Middle Ages in different parts of the world. The oldest soda ash glasses originated from ancient Mesopotamia and Egypt. Glass produced in central Europe and Venice between $11^{\text {th }}$ to $14^{\text {th }}$ centuries frequently reflects soda ash glass composition [4-6]. Typical soda ash glass contains sodium and calcium oxides in a weight proportion of almost 1.4:1 and relatively high amount of magnesium and potassium oxides due to use of quartz and the ash of halophytic plants for production [4-7]. Soda lime glass was produced from $900 \mathrm{BC}$ to the Middle Ages from quartz, trona and lime. Generally soda lime glass is characteristic for Roman glass and can be found also in post-Roman buildings and places. Low potassium and magnesium oxides concentration with high content of sodium and calcium oxides is typical of soda lime glasses $[4,5$, $8,9]$.

In the $8^{\text {th }}$ century, glass production was established on the basis of quartz and ash from beech trunks or from bulk beech trees. As a consequence of the use of such raw materials, elevated amounts of silicon, potassium and calcium oxides were found. In central Europe, during the Middle Ages, several subtypes of wood ash glasses were produced and they can be distinguished by the ratio of $\mathrm{CaO}$ vs. $\mathrm{K}_{2} \mathrm{O}$ [3]. The monk Theophilus Prestyber in his Diversarum Artium Schedula prescribed a wood ash glass recipe, where he suggested to mix and melt two parts ash of beech trunks with one part of quartz sand [3]. If producers follow that recipe, glass should contain no more than $50 \% \mathrm{SiO}_{2}$ and about $20 \% \mathrm{~K}_{2} \mathrm{O}$ [5]. Similar concentration of $\mathrm{CaO}$ and $\mathrm{K}_{2} \mathrm{O}$ is considered to be the evidence of the manufacture of glass with alkaline ashes obtained from good quality, purified wood with a low amount of bark. Medieval glass panels from English and French churches are characterized by higher concentrations of magnesium and phosphorus oxides in comparison to glass produced in Germany $[5,10]$. Wood ashes were used in the production of glass until the $19^{\text {th }}$ century. Therefore, discrimination of glass produced through the ages can be based on the ratio of specific elements [3]. Medieval glass technology utilized different materials and techniques for gaining specific colour of glass $[3,11]$.

Archaeometric research, defined as the application of scientific techniques and methodologies to archaeology and arts, provides important data for art historians, conservators and other professionals dealing with historical objects. Information about elemental composition of glass is necessary to determine the type of glass, the technology and provenance of the object. The determination of changes in the elemental composition of glass, which occurred due to deterioration processes, is vital for the proper evaluation of the condition of glass. Such information is 
also very important to establish appropriate conservation treatment. Many analytical methods can be applied for the investigations of glass samples. Scanning Electron Microscope coupled with an Energy Dispersive $\mathrm{X}$-Ray spectrometry (SEM-EDX) enables for measuring the content of main elements, but does not provide information on trace elements content, which can be essential for the provenance studies of historical glass. One of the methods allowing the identification of trace elements without sample preparation is Laser Ablation Inductively Coupled Plasma Mass Spectrometry (LA-ICP-MS).

This paper focuses on two stained glass panels from the so-called Grodziec Collection. A part of that collection consists of a group of fourteen panels, most likely of Austrian origin, depicting figures on architectural backgrounds, and is dated to $1420-1425$. There is no information on the time and person who brought the collection to Grodziec. Moreover, it is not clear whether the figurative panels embellished the windows of the castle, palace or the tower (Fig. 1) [12]. After the Second World War, eight panels were relocated to Kraków and are actually held by the Jagiellonian University Museum. The remaining six are held by the
National Museum in Wrocław where they were transported in 1966 [12]. Primarily the glass panels were determined as $19^{\text {th }}$-century copies. Later-on, the analyses performed during the conservation of the panels from the Jagiellonian University Museum in Kraków (2000-2004) and those from the National Museum in Wrocław (2013-2014) indicated medieval origins, modern composition of some of the glass panes and similarity of the panels. Further studies based on the analysis of historical documents and photos $[12,13]$, visual inspection of the glass panes, paints, leadlight glazing and physicochemical analyses performed by X-Ray Fluorescence (XRF), macro-XRF, micro-Raman spectroscopy, SEM-EDX, Optical Coherence Tomography [14-16] revealed more information about history, origin and degradation of the collection.

A detailed analysis of two medieval stained glass panels from the Grodziec collection was performed to determine the subtype of the medieval glass, confirm the provenance of the objects and indicate the accuracy of the production. Elemental composition of bulk glass and external layers of glass samples was determined using SEMEDX and LA-ICP-MS methods. The methods

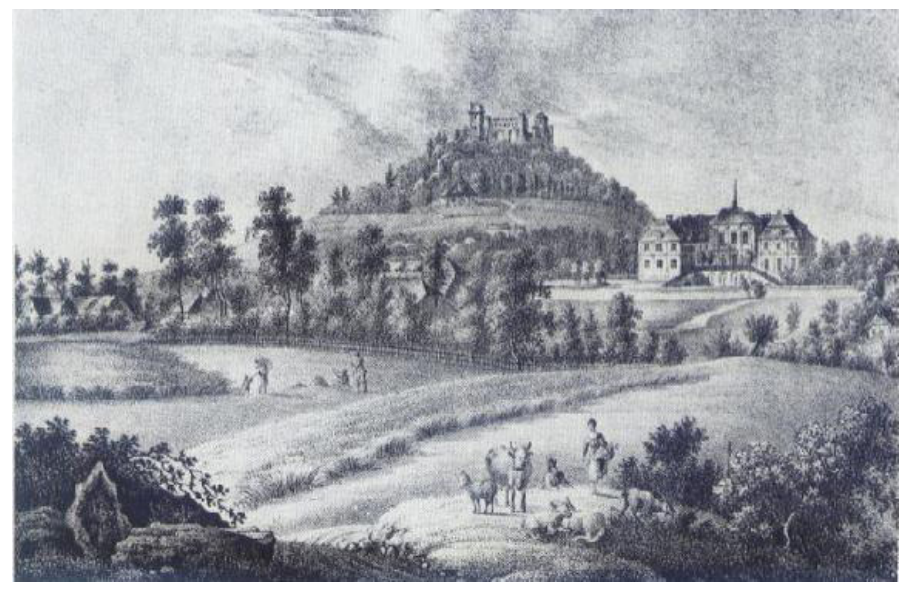

Fig 1. Historic buildings in Grodziec: castle on the hill and baroque palace (lithography from 1837). 
are capable to deliver information about the elemental composition and the state of the preservation of medieval glass due to chemical imaging (mapping). Additionally, LA-ICP-MS method allows for high spatial resolution measurements and for determination of trace elements. Morphology of the deteriorated glass was investigated through SEM-BSE (Backscattered Electrons) images of the cross-sections. LA-ICP-MS longitudinal concentration profiles were carried out to

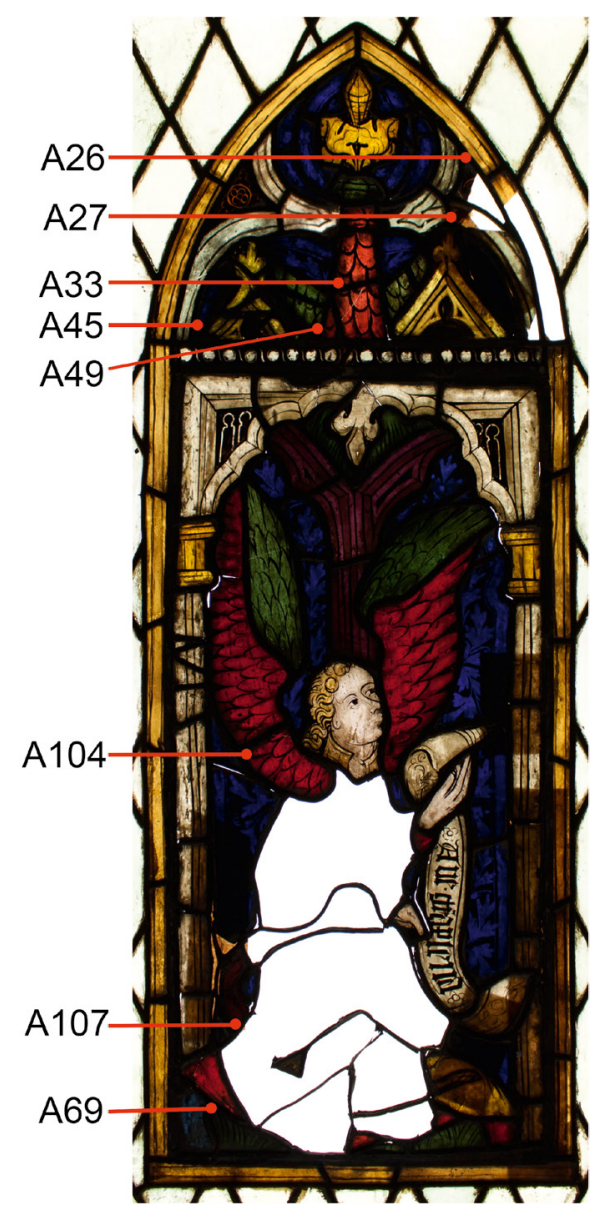

Fig. 2. Stained glass panel representing Annunciation Archangel Gabriel; Styria \& Carinthia, about 1430; samples collected from different glasses for the analysis are indicated by a number and arrows. reveal technology used to produce red glasses and corrosion phenomena.

\section{Materials and methods}

Two stained glass panels from Grodziec collection representing Annunciation Archangel Gabriel and St. Barbara (Fig. 2,3) were selected for the study. Nowadays, they belong to the collection of the National Museum in

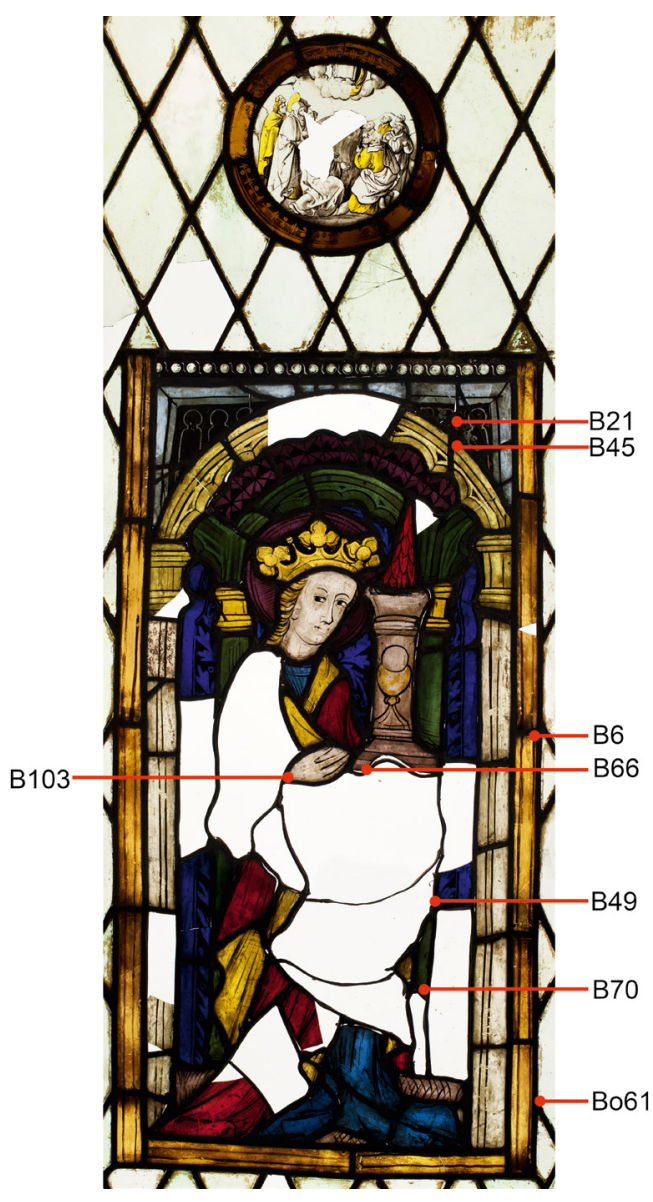

Fig. 3. Stained glass panel representing St. Barbara; Styria \& Carinthia, about 1430; samples collected from different glasses for the analysis are indicated by a number and arrows. 
Wrocław. Each panel has around $117 \mathrm{~cm}$ high and $43 \mathrm{~cm}$ width. According to historical data, those panels were manufactured about 1430 by stained glass workshop operated on the border between Styria and Carinthia in Austria [13].

Since many of glass pieces are broken, there was a possibility to prepare very small samples $\left(0,25 \mathrm{~cm}^{2}\right)$ for investigations. Samples differed with colour (yellow, red, blue, green) were selected from various parts of the panels and marked by a number. Three samples were selected from outside areas of the panels and glazing (A26, A27, Bo61). Location of the samples at the windows is presented in Figs. 2 and 3. Samples were immersed in epoxy resin and polished to receive thick sections.

Elemental composition was determined using laser ablation system (LSX-213 from Teledyne Cetac Technologies, USA) coupled with inductively coupled plasma mass spectrometer (NexION 300D from Perkin Elmer SCIEX, Canada). An LSX-213 system at $213 \mathrm{~nm}$ UV laser (Nd-YAG, solid state, Q-switched) with maximum energy up to 5 $\mathrm{mJ} /$ pulse and $5 \mathrm{~ns}$ pulse width was used for ablation. All experiments were performed using $\mathrm{Ar}$ as the carrier gas. Instrumental settings and data acquisition parameters are given in Table 1. Sample ablation was performed using different parameters. The spot diameter was adjusted to $100 \mu \mathrm{m}$ and pulse repetition rate adjusted to $10 \mathrm{~Hz}$ only for bulk analysis of the glass. The analyses of specific areas of the samples, i.e. colour or corroded layers, were carried out using smaller laser diameter $(25 \mu \mathrm{m})$ and higher pulse repetition rate $(20 \mathrm{~Hz})$. A number of experiments were performed to collect time resolved line profiles across different zones within a single sample. For these experiments the laser spot and scan rate were adjusted to $25 \mu \mathrm{m}$ and $1 \mu \mathrm{m} \cdot \mathrm{s}^{-1}$ respectively.

At least three replicate ablations at positions randomly selected were carried out on each sample. Transient signals were recorded and evaluated for elemental quantification.

Table 1. Instrumental settings and data acquisition parameters for LA-ICP-MS method

\begin{tabular}{|c|c|c|c|}
\hline \multicolumn{2}{|c|}{ ICP-MS characteristics and settings } & \multicolumn{2}{|c|}{ Laser ablation characteristics and settings } \\
\hline RF Power, $(\mathrm{W})$ & 1200 & Type of laser & Nd:YAG 213nm \\
\hline Neb. gas flow rate, $\left(\mathrm{L} \mathrm{min}^{-1}\right)$ & 0.94 & Pulse duration (ns) & 5 \\
\hline \multirow{2}{*}{ Carrier gas } & Ar & Energy (mJ) & 5.0 \\
\hline & & Ablation mode & spot, line \\
\hline \multicolumn{2}{|c|}{ ICP-MS data acquisition parameters } & Beam diameter $(\mu \mathrm{m})$ & $100 / 25$ \\
\hline Scanning mode & Peak hopping & Pulse repetition rate $(\mathrm{Hz})$ & $10 / 20$ \\
\hline Readings & 1 & Scan rate $\left(\mu \mathrm{m} \mathrm{s}^{-1}\right)$ & \\
\hline Replicates & 250 & (line mode only) & 1 \\
\hline Sweeps & 1 & & \\
\hline Dwell time, (ms) & 5 & & \\
\hline Pre-integration time, $(\mathrm{s})$ & 30 & & \\
\hline Integration time, $(\mathrm{s})$ & 60 & & \\
\hline Isotopes monitored & \multicolumn{3}{|c|}{$\begin{array}{l}{ }^{7} \mathrm{Li},{ }^{23} \mathrm{Na},{ }^{24} \mathrm{Mg},{ }^{27} \mathrm{Al},{ }^{29} \mathrm{Si},{ }^{39} \mathrm{~K},{ }^{43} \mathrm{Ca},{ }^{45} \mathrm{Sc},{ }^{49} \mathrm{Ti},{ }^{51} \mathrm{~V},{ }^{52} \mathrm{Cr},{ }^{55} \mathrm{Mn},{ }^{57} \mathrm{Fe},{ }^{59} \mathrm{Co}, \\
{ }^{60} \mathrm{Ni}{ }^{65} \mathrm{Cu},{ }^{66} \mathrm{Zn},{ }^{69} \mathrm{Ga},{ }^{85} \mathrm{Rb},{ }^{88} \mathrm{Sr},{ }^{89} \mathrm{Y},{ }^{90} \mathrm{Zr},{ }^{93} \mathrm{Nb},{ }^{118} \mathrm{Sn},{ }^{121} \mathrm{Sb},{ }^{137} \mathrm{Ba},{ }^{139} \mathrm{La}, \\
{ }^{140} \mathrm{Ce},{ }^{141} \mathrm{Pr},{ }^{142} \mathrm{Nd},{ }^{152} \mathrm{Sm},{ }^{153} \mathrm{Eu},{ }^{158} \mathrm{Gd},{ }^{159} \mathrm{~Tb},{ }^{164} \mathrm{Dy},{ }^{165} \mathrm{Ho},{ }^{166} \mathrm{Er},{ }^{169} \mathrm{Tm}, \\
{ }^{174} \mathrm{Yb},{ }^{175} \mathrm{Lu},{ }^{178} \mathrm{Hf},{ }^{181} \mathrm{Ta},{ }^{202} \mathrm{Hg},{ }^{207} \mathrm{~Pb},{ }^{208} \mathrm{~Pb},{ }^{232} \mathrm{Th},{ }^{238} \mathrm{U}\end{array}$} \\
\hline
\end{tabular}


NIST SRM 610 [17] and Corning D archeological glass [18] were used as the external standard for modern and medieval objects respectively. The results of elemental composition, for all samples, were recalculated to the content of the oxides using $\mathrm{SiO}_{2}$ as the internal standard. Sum normalization to 100 $\mathrm{wt} \%$ was applied based on the corresponding oxide concentrations [19]. The accuracy of the measurements was established by using Corning B archeological glass examined as an unknown sample.

The composition and morphology of glasses were examined by SEM-EDX (JEOL $5500 \mathrm{LV}$, Japan). The imaging was performed with $20 \mathrm{keV}$ electron beam. Prior to SEM imaging the glass sample was covered with thin carbon layer to avoid charging of the sample surface. The chemical composition of glass bulk and corrosion layers was determined by EDX (IXRF Systems, USA). Magnification from 200 to 900 times and live time of $50 \mathrm{~s}$ were adjusted during the analysis.

\section{Results and discussion}

\subsection{Elemental composition of modern and medieval samples}

Firstly, the bulk analysis of glass samples was carried out by using LA-ICP-MS and SEM-EDX methods to determine the concentration of major and minor elements. The analytical results obtained by the LA-ICP-MS are given in Table 2. Comparative data obtained for two selected red and green stained glasses from the analysis by using SEM-EDX and LA-ICP-MS methods are presented in Table 3.

As shown in Table 3, the results for the oxide content obtained with both techniques are generally in good agreement for most of the elements. However, some differences between the average of oxide content should be emphasized. Especially, differences for $\mathrm{CaO}, \mathrm{MgO}$ and $\mathrm{Al}_{2} \mathrm{O}_{3}$ contents are evident (about 20\% and 10\% relative error for red and green sample respectively). Similar errors were observed in the earlier complementary analysis of historical glass by SEM-EDX and LA-ICP-MS [20]. It can be explained by different sensitivities of those two techniques as well as due to different sampling zones used for signal acquisition [20,21]. It is well known that SEM-EDX gives information from deeper and larger volumes of the exposed matter. This is especially important when historical glasses are analyzed, as the concentration gradients between the surface and sub-surface regime of the glasses objects occurs due to weathering. Additionally, elemental fractionation during LA-ICP-MS analysis may play an important role during the analysis of transparent materials. For transparent glasses LA-ICP-MS analyses showed progressive volatility dependence with increasing transparency and measured concentrations of refractory elements being lower. On the other hand, measured concentrations of volatile elements being higher in comparison to certified concentrations of reference materials [22]. Thus, higher differences in results obtained from LA-ICP-MS and SEM-EDX analyses for red glass can be associated with higher transparency of red medieval glass in comparison to green glass. It is also worth reminding that phosphorus oxide was not detected in LA-ICP-MS due to the presence of a high background signal.

The accuracy of LA-ICP-MS measurements was established by using Corning $B$ archeological glass examined as an unknown sample. The composition of Corning Glass B measured by LA-ICP-MS in present study is 
Table 2. Composition of Grodziec stained glasses - concentrations of oxides in mass\% (average with standard deviation (SD) and range values in all measured samples by LA-ICP-MS)

\begin{tabular}{|c|c|c|c|c|c|c|}
\hline \multirow[t]{2}{*}{ wt. \% } & \multicolumn{3}{|c|}{$\begin{array}{l}\text { medieval samples } \\
\text { (13 samples) }\end{array}$} & \multicolumn{3}{|c|}{$\begin{array}{c}\text { modern samples } \\
\text { (3 samples: A26, A27, Bo61) }\end{array}$} \\
\hline & mean & SD & range & mean & SD & $\max$ \\
\hline $\mathrm{SiO}_{2}$ & 48.37 & 0.76 & $46.58 \div 49.09$ & 71.55 & 2.33 & $68.89 \div 73.25$ \\
\hline $\mathrm{Na}_{2} \mathrm{O}$ & 0.156 & 0.023 & $0.134 \div 0.212$ & 15.80 & 1.64 & $14.51 \div 17.65$ \\
\hline $\mathrm{MgO}$ & 3.46 & 0.09 & $3.22 \div 3.61$ & 0.240 & 0.068 & $0.163 \div 0.288$ \\
\hline $\mathrm{Al}_{2} \mathrm{O}_{3}$ & 1.00 & 0.12 & $0.82 \div 1.25$ & 0.428 & 0.010 & $0.422 \div 0.440$ \\
\hline $\mathrm{K}_{2} \mathrm{O}$ & 22.52 & 0.85 & $21.69 \div 25.24$ & 0.189 & 0.003 & $0.185 \div 0.190$ \\
\hline $\mathrm{CaO}$ & 22.35 & 0.60 & $20.11 \div 23.44$ & 11.33 & 0.174 & $11.21 \div 11.53$ \\
\hline $\mathrm{TiO}_{2}$ & 0.116 & 0.005 & $0.102 \div 0.126$ & 0.059 & 0.002 & $0.057 \div 0.060$ \\
\hline $\mathrm{MnO}$ & 0.768 & 0.082 & $0.635 \div 1.227$ & 0.374 & 0.594 & $0.031 \div 1.059$ \\
\hline $\mathrm{Fe}_{2} \mathrm{O}_{3}$ & 0.570 & 0.558 & $0.262 \div 2.128$ & & & \\
\hline $\mathrm{Li}_{2} \mathrm{O}$ & 0.0025 & 0.0007 & $0.0018 \div 0.0040$ & 0.0020 & 0.0005 & $0.0017 \div 0.0026$ \\
\hline $\mathrm{V}_{2} \mathrm{O}_{5}$ & 0.0010 & 0.0001 & $0.0008 \div 0.0012$ & 0.0011 & 0.0005 & $0.0009 \div 0.0017$ \\
\hline $\mathrm{CoO}$ & 0.0427 & 0.0694 & $0.0005 \div 0.1747$ & & & \\
\hline $\mathrm{NiO}$ & 0.0166 & 0.0207 & $0.0012 \div 0.0551$ & & & \\
\hline $\mathrm{CuO}$ & 0.0619 & 0.0662 & $0.0123 \div 0.1833$ & 0.0023 & - & \\
\hline $\mathrm{ZnO}$ & 0.0426 & 0.0036 & $0.0391 \div 0.0485$ & & & \\
\hline $\mathrm{Ga}_{2} \mathrm{O}_{3}$ & & & & 0.0008 & - & \\
\hline $\mathrm{Rb} 2 \mathrm{O}$ & 0.1181 & 0.0092 & $0.1019 \div 0.1469$ & & & $0.0003 \div 0.0004$ \\
\hline $\mathrm{SrO}$ & 0.0985 & 0.0098 & $0.0627 \div 0.1100$ & 0.0068 & 0.0003 & $0.0064 \div 0.0071$ \\
\hline $\mathrm{ZrO}_{2}$ & 0.0030 & 0.0004 & $0.0024 \div 0.0037$ & 0.0045 & 0.0006 & $0.0041 \div 0.0052$ \\
\hline $\mathrm{SnO}_{2}$ & 0.0045 & 0.0130 & $0.0000 \div 0.0416$ & 0.0008 & 0.0007 & $0.0004 \div 0.0016$ \\
\hline $\mathrm{Sb}_{2} \mathrm{O}_{5}$ & & & & 0.0009 & 0.0009 & $0,0003 \div 0,0015$ \\
\hline $\mathrm{BaO}$ & 0.3081 & 0.0443 & $0.1498 \div 0.3818$ & 0.0127 & 0.0078 & $0.0081 \div 0.0216$ \\
\hline $\mathrm{La}_{2} \mathrm{O}_{3}$ & & & & 0.0002 & - & \\
\hline $\mathrm{PbO}$ & 0.0021 & 0.0023 & $0.0008 \div 0.0084$ & 0.0148 & - & \\
\hline
\end{tabular}

compared to compositions published by Brill [23], Dussubieux et al. [24] and Wagner et al. [18] in Table 4 . The data clearly show that accuracy strongly differs for each element and depends on selected external standard for quantification. Relatively good accuracy is observed for trace elements and many major oxides, i.e. $\mathrm{SiO}_{2}, \mathrm{MgO}, \mathrm{CaO}, \mathrm{FeO}$ and $\mathrm{MnO}$, when Corning Glass D was used as external standard. Contrary, accuracy for $\mathrm{Al}_{2} \mathrm{O}_{3}, \mathrm{~K}_{2} \mathrm{O}$ and $\mathrm{Na}_{2} \mathrm{O}$ is low, which is expressed in high value of error. It should be underline that the difference in composition of Corning $\mathrm{B}$ and $\mathrm{D}$ glasses is pronounced for $\mathrm{K}_{2} \mathrm{O}$ and $\mathrm{Na}_{2} \mathrm{O}$.
Thus, lower accuracy for such oxides can be explained by use of non-matrix matched Corning Glass $\mathrm{D}$ for quantification of Corning Glass B. Because $\mathrm{K}_{2} \mathrm{O}$ and $\mathrm{Na}_{2} \mathrm{O}$ content in NIST 610 and Corning Glass B is much more similar, better accuracy for such oxides is observed (Table 4). The assessment of the accuracy indicates the importance of selection of matrix-matched reference materials for the analysis by LA-ICP-MS and allows to assume that results for analyzed samples are reliable due to good match of Corning Glass $\mathrm{D}$ and NIST610 to medieval and modern glasses respectively. 
Table 3. Element concentrations (average value \pm SD) for two selected samples obtained by SEM-EDX and LA-ICP-MS analyses

\begin{tabular}{lcccc}
\hline \multirow{2}{*}{$w t . \%$} & \multicolumn{2}{c}{ red glass (A104) } & \multicolumn{2}{c}{ green glass (A49) } \\
\cline { 2 - 5 } & SEM-EDX & LA-ICP-MS & SEM-EDX & LA-ICP-MS \\
\hline $\mathrm{SiO}_{2}$ & $50.30 \pm 0.60$ & $48.39 \pm 0.21$ & $51.23 \pm 0.38$ & $47.67 \pm 0.53$ \\
$\mathrm{Na}_{2} \mathrm{O}$ & & $0.135 \pm 0.001$ & & $0.208 \pm 0.008$ \\
$\mathrm{~K}_{2} \mathrm{O}$ & $20.00 \pm 0.27$ & $21.69 \pm 0.10$ & $19.63 \pm 0.05$ & $21.98 \pm 0.39$ \\
$\mathrm{CaO}$ & $19.73 \pm 0.25$ & $23.44 \pm 0.33$ & $20.16 \pm 0.09$ & $21.81 \pm 0.85$ \\
$\mathrm{MgO}$ & $2.99 \pm 0.13$ & $3.61 \pm 0.08$ & $3.22 \pm 0.26$ & $3.42 \pm 0.03$ \\
$\mathrm{Al}_{2} \mathrm{O}_{3}$ & $1.26 \pm 0.14$ & $1.01 \pm 0.02$ & $1.42 \pm 0.04$ & $1.24 \pm 0.05$ \\
$\mathrm{P}_{2} \mathrm{O}_{5}$ & $0.98 \pm 0.03$ & & $1.04 \pm 0.07$ & \\
$\mathrm{MnO}$ & $0.79 \pm 0.08$ & $0.74 \pm 0.03$ & & $0.736 \pm 0.005$ \\
$\mathrm{FeO}$ & 0.40 & $0.29 \pm 0.01$ & $2.06 \pm 0.03$ & $2.11 \pm 0.04$ \\
$\mathrm{TiO}_{2}$ & 0.34 & $0.121 \pm 0.002$ & & $0.123 \pm 0.004$ \\
\hline
\end{tabular}

The content of main elements allows to divide the glasses in two different groups, which means that the panels consist of glass parts originated from different centuries. Three samples taken from outside areas of the panels and from the glazing (denoted as A26, A27, Bo61; Fig. 2, 3) exhibit typical composition of soda lime glass. The high content of $\mathrm{SiO}_{2}, \mathrm{Na}_{2} \mathrm{O}$ and $\mathrm{CaO}$ and low content of other oxides reflecting the modern origins of the glasses. Thus, results confirm that some glasses in the panels and the leadlight glazing were added at the beginning of the $20^{\text {th }}$ century, most probably due to conservation works.

It is worth noticing that medieval and modern samples can be separated by main oxides content. Cluster analysis was employed for visualization of the data structure for analyzed glasses according to Zadora et al. [25]. $\mathrm{Na}, \mathrm{Mg}, \mathrm{Al}, \mathrm{Si}, \mathrm{K}$ and $\mathrm{Ca}$ content was used to describe objects. The distance between objects was calculated using Euclidean measure after autoscaling the data and Ward's algorithm was applied as the linkage method for clustering. The dendrogram presented on Fig. 4 clearly shows two different kinds of glass - medieval and modern. Especially, comparison of $\mathrm{SiO}_{2}, \mathrm{Na}_{2} \mathrm{O}, \mathrm{CaO}$ and $\mathrm{K}_{2} \mathrm{O}$ contents allows for distinction of medieval glasses (soda ash, soda lime and wood ash) and modern glasses with the greatest confidence. Modern glass (i.e. soda lime glass) contains the highest amount of $\mathrm{SiO}_{2}$ (above

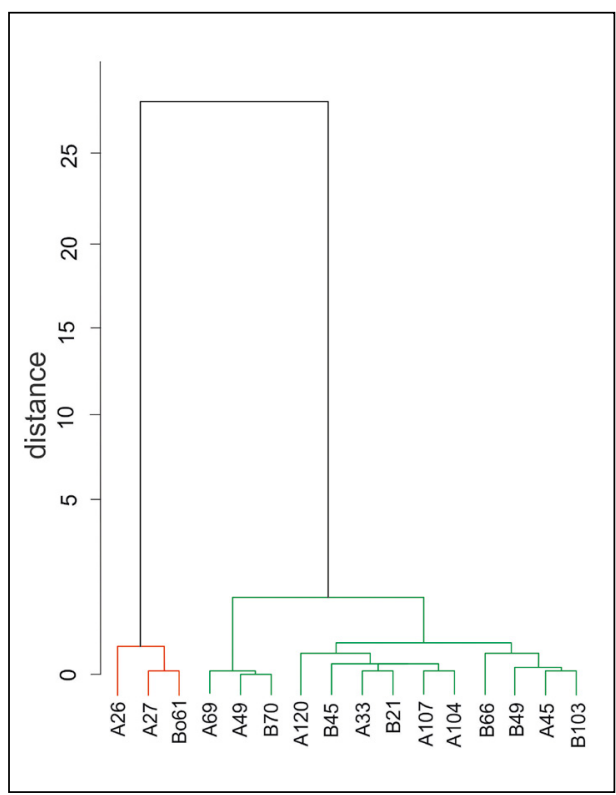

Fig. 4. The dendrogram for glass data including modern (A26, A27, Bo61) and medieval (other samples) glass. 
Table 4. Comparison between the composition of Corning Glass B measured by LA-ICP-MS in the present study with reproducibility (standard deviation) and accuracy (relative error based on mean value from published data) and composition published by Brill [23], Dussubieux et al. [24] and Wagner et al. [18]

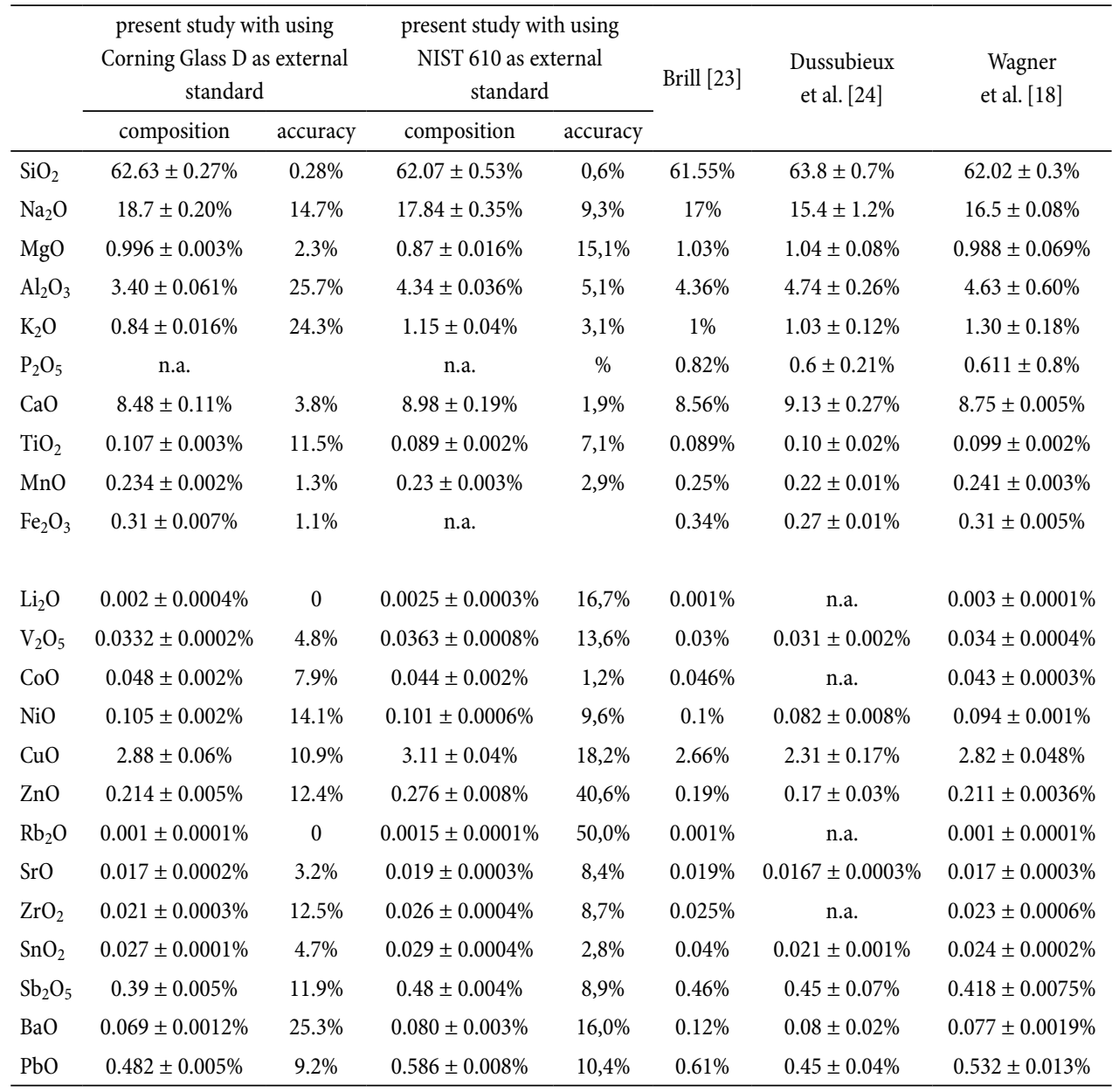

$70 \%)$ and very low amount of $\mathrm{K}_{2} \mathrm{O}$ in comparison to medieval glasses [3].

Big differences in elemental composition allows for classification glasses as medieval (i.e. wood ash glass) or modern. Because only 16 samples were analyzed, likelihood ratio models cannot be applied. Nevertheless, relatively simple Hotelling's $\mathrm{T}^{2}$ test was applied to check statistical confidence of classification based on elemental composition, i.e. multivariate data. Medieval sample A104 was randomly selected for calculations. The content of six major elements $(\mathrm{Na}, \mathrm{Mg}, \mathrm{Al}$, $\mathrm{Si}, \mathrm{K}$ and $\mathrm{Ca}$ ) was transformed by taking the logarithm to base 10. Composition of sample A104 was used as object A and composition of other medieval samples was acknowledged as object $\mathrm{B}$. The $p$-value calculated in $\mathrm{R}$ software (www.r-project.org) is 0.1124 , which suggests strongly that A104 is medieval glass. 
This means that the content of major elements is suitable for discrimination of wood ash and modern glass. On the other hand, the content of trace elements has a significant impact mainly for the discrimination of glasses manufactured in similar periods or provenance studies.

The great majority of analysed glasses have medieval origins. The oldest glass of the stained-glass panels from Grodziec is typical medieval wood ash glass. The amount of $\mathrm{SiO}_{2}$ is close to $50 \%$, while $\mathrm{CaO}$ and $\mathrm{K}_{2} \mathrm{O}$ content is around $40 \%$ (Table 2). The remaining oxides are present in an amount of around $10 \%$. The similar content of $\mathrm{CaO}$ and $\mathrm{K}_{2} \mathrm{O}$, that is $\mathrm{CaO} / \mathrm{K}_{2} \mathrm{O}$ ratio equals to 1 , is the evidence of the use of alkaline ashes obtained from good quality, purified wood with a low amount of bark [3]. That would also explain the relatively low phosphorus content in glass (Table 3 ). The results confirm that composition of the glasses is typical to $10^{\text {th }}-14^{\text {th }}$ century medieval glass and manufacturers had applied Theophilus recipe very strictly [3]. Low contents of $\mathrm{MgO}$ and $\mathrm{Na}_{2} \mathrm{O}$ (around $3.5 \%$ and $0.16 \%$ respectively) are consistent with the composition of stained glasses from the $12^{\text {th }}$ to $14^{\text {th }}$ centuries from Germanic countries. In agreement with literature data, these chemical differences give opportunity to distinguish Grodziec collection panels from French medieval glass [10]. Also $\mathrm{TiO}_{2}$ content ranging from 0.10 to $0.13 \%$ and $\mathrm{BaO}$ content ranging from 1498 to $3818 \mathrm{ppm}$ are characteristic of medieval wood ash glass [3].

An important observation can be made by considering differences in the concentration of minor and trace elements for all measured medieval samples (Fig. 5). There are no significant differences in the content of several oxides $\left(\mathrm{TiO}_{2}, \mathrm{~V}_{2} \mathrm{O}_{5}, \mathrm{MnO}, \mathrm{ZnO}, \mathrm{Rb}_{2} \mathrm{O}, \mathrm{SrO}\right.$, $\mathrm{BaO}$ ) related to raw materials, i.e. quartz sand and beech ash. Similar content of such oxides in all samples suggests the same source or the same recipe applied for the production of glass.

Contrary, significant differences in oxide concentrations are observed for colorants and related chemicals, i.e. $\mathrm{Fe}_{2} \mathrm{O}_{3}, \mathrm{CoO}, \mathrm{NiO}$ and $\mathrm{CuO}$. The green color of samples was evidently obtained with iron compounds (average concentration of $\mathrm{Fe}_{2} \mathrm{O}_{3}$ for three green samples is $2.11 \%$ ) and copper compounds (about $579 \mathrm{ppm} \mathrm{CuO}$ ). Blue glass was obtained by addition of $\mathrm{CoO}$ (ranging from $431 \mathrm{ppm}$ to $1747 \mathrm{ppm}$ ) and was characterized by a $\mathrm{Fe}_{2} \mathrm{O}_{3}$ content in the range between $0.4 \%$ and $0.7 \%$. The results are consistent with the composition of glass colorants used in the Middle Ages [1-3, 9, 20]. Nevertheless, yellow and red glasses are

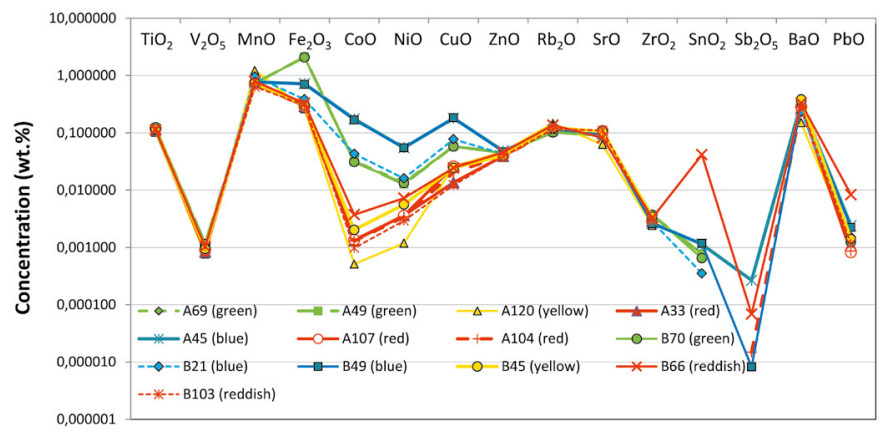

Fig. 5. The concentration of minor and trace elements in Grodziec medieval samples. 
not distinguishable from results obtained from bulk analyses.

It is worth noticing that green samples (A69, A49 and B70) from two stained glass panels exhibit almost the same composition. Similar observation can be stated for blue samples (A45 and B49) and red and yellow samples (A33, A104, A107, A120, B45, B66, B103). Exceptionally high content of $\mathrm{SnO}_{2}$ is observed in B66 sample, which can be explained by contamination during manufacture of glass or the panel. Such clear similarity of the samples confirms that stained glasses were produced at the same time from the same sources.

\subsection{Composition of medieval red samples}

Red colour of wood ash glasses was usually obtained by additions of about 0.1 to $0.5 \% \mathrm{Cu}$

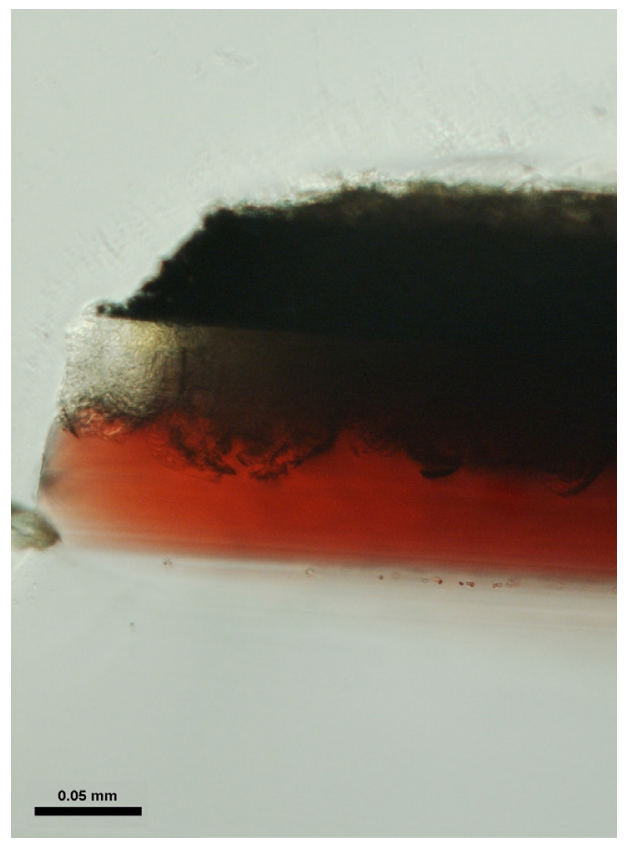

Fig. 6a. Microscopic view on cross-section of the red sample (A107) showing three separate layers (bar length: $0.05 \mathrm{~mm}$ ). to glass melts $[1,2]$. Results from bulk analysis of red samples indicate that the Grodziec glasses contain average $194 \mathrm{ppm}$ of $\mathrm{CuO}$. Thus copper content according to published literature should be expected to be present in a more distinctive amount [11]. Nevertheless, microscopy and SEM studies clarify composition and structure of red samples. Grodziec red glasses are mainly composed with three separate layers (Fig. 6a, 6b and 7). The biggest and innermost layer of the glass is colourless. As this layer was analysed during bulk analysis of red glasses by SEM-EDX and LA-ICP-MS, concentrations of oxides usually used as colorants were similar to slightly yellowish glasses (Fig. 5 and Table 5). Intensive red layer is located quite close to the surface of glass (Fig. 6a). The thin red layer is responsible for overall colour of the glass and contains higher amount of copper

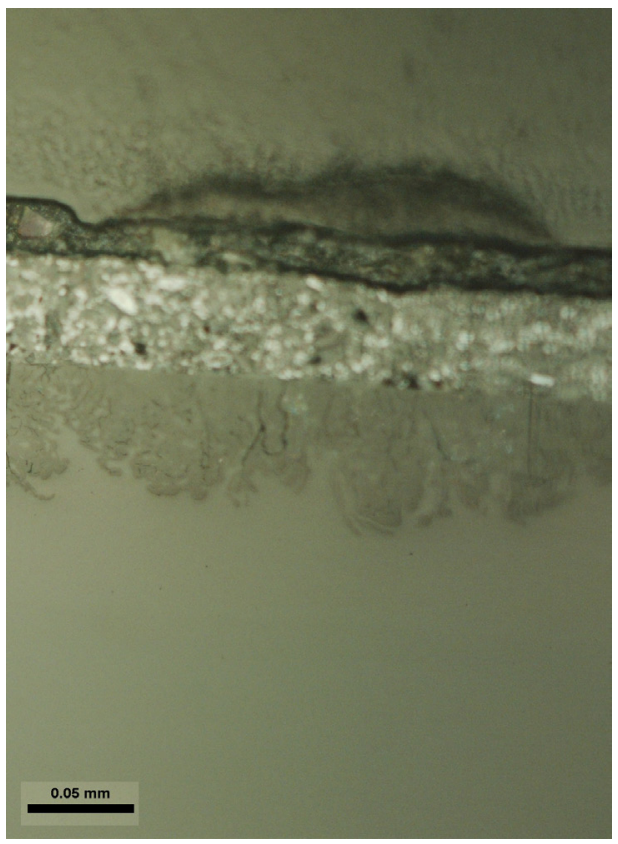

Fig. 6b. Microscopic view (in transparent light) on cross-section of the red sample (A107) showing three separate layers (bar length: $0.05 \mathrm{~mm}$ ). 
Table 5. Average concentrations of selected elements in different layers in the red glass (sample A107)

\begin{tabular}{llllll}
\hline wt.\%: & $\mathrm{CuO}$ & $\mathrm{Fe}_{2} \mathrm{O}_{3}$ & $\mathrm{PbO}$ & $\mathrm{CaO}$ & $\mathrm{SiO}_{2}$ \\
\hline outside colourless glass layer & 46 & 1.5 & 6.4 & 18.7 & 19.2 \\
red layer & $\mathbf{0 . 4 9}$ & 0.20 & 0.0407 & 20.9 & 51.7 \\
inside colourless glass layer & 0.026 & 0.29 & 0.0008 & 22.7 & 48.7 \\
\hline
\end{tabular}

(about $0.5 \% \mathrm{CuO}$ ). Thus the composition of the layer is agreed with the literature data $[3,4]$. Third additional colourless layer is overlaying the red. Such composition and structure of the glass is consistent with type B-3 red translucent glass, which was commonly applied from the $12^{\text {th }}$ century [11]. High amount of copper, iron and lead in the third layer (Table 5) can be explained with the presence of decorative paint layers and drawings [20].

The composition of the outside layers is affected also by corrosion processes manifested by microcracks, as can be seen on microscopic and BSE-SEM images (Fig. 6b, 7). This reflects in changes in the concentration of some elements in areas located near the surface of the glass. LA-ICP-MS longitudinal concentration profiles carried out from

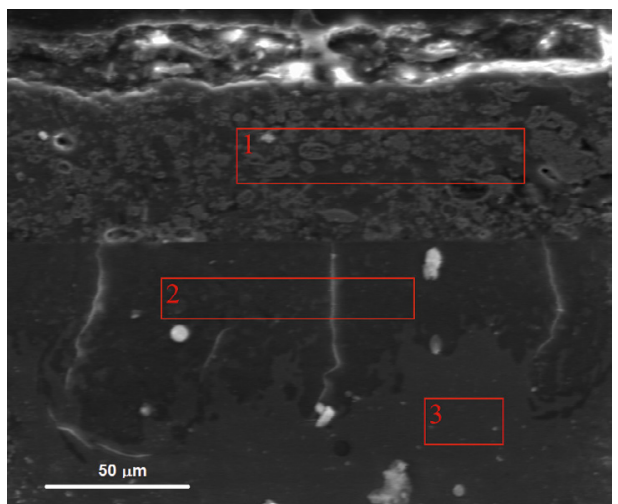

Fig. 7. BSE-SEM image showing different layers in the glass sample (A107): paint layer with the corrosion crust (1), outside colourless layer (2) and red layer (3). inside the glass to outside layers clearly show differences (Fig. $8 \mathrm{a}$ and $8 \mathrm{~b}$ ). $\mathrm{SiO}_{2}$ is enriched at the surface, while $\mathrm{CaO}$ and $\mathrm{K}_{2} \mathrm{O}$ shows decreasing concentration from the bulk to the surface of the glass (Fig. 8a).

Thus $\mathrm{Ca}$ and $\mathrm{K}$-ions are leached out of the glass, which is a typical result of glass

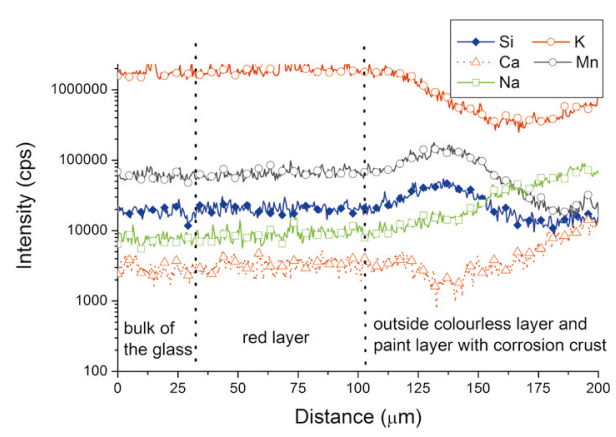

Fig. 8a. Longitudinal concentration profiles of alkali and manganese carried out from inside to outside layers in the red sample (A107).

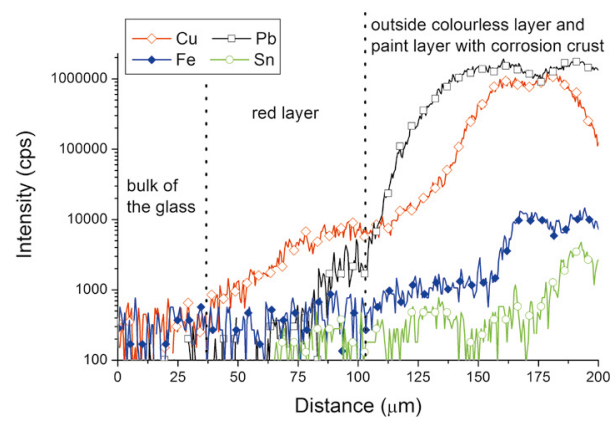

Fig. 8b. Longitudinal concentration profiles of elements related to paints carried out from inside to outside layers in the red sample (A107). 
deterioration caused by an ion exchange between $\mathrm{H}$-ions in water deposited on the glass surface. Enrichment of $\mathrm{SiO}_{2}$ at the surface is a result of increasing density of glass surface due to depletion of alkaline ions $[26,27]$. Nevertheless, $\mathrm{Na}_{2} \mathrm{O}$ enrichment at the surface (Fig. 8a) is not agreed with the well-known glass deterioration mechanism, because depletion of the $\mathrm{Na}_{2} \mathrm{O}$ as the most mobile alkaline is expected [27]. It can be explained only by low concentration of $\mathrm{Na}_{2} \mathrm{O}$ in wood ash glass and possible presence of sodium in paint layers. However, further studies are needed to clarify the result. The concentration of $\mathrm{MnO}$ in external surfaces is higher in comparison to the bulk, which can be explained by manganese browning [16]. The presence of high content of $\mathrm{Cu}, \mathrm{Pb}, \mathrm{Fe}$ and $\mathrm{Sn}$ in the outside colourless layers (Fig. $8 b$ ) is caused by the diffusion process from the paint layer

\section{Conclusions}

The applied analytical methods provided valuable information on the composition of Grodziec stained glasses, which was necessary to perform provenance studies of the investigated panels. Results confirm that stained glass panels reveal characteristic elemental composition of wood ash glass produced from 1000 to $1400 \mathrm{AD}$. Almost equal proportions of potassium and calcium oxides indicate that high quality of beech wood was applied by manufacturers. Main elements content is similar for almost all investigated glass samples, which means that manufacturers follow strictly the assumed recipe during panels production. Some glasses exhibit typical composition of modern glass, which were probably used during conservation treatments at $19^{\text {th }}$ or $20^{\text {th }}$ centuries.
LA-ICP-MS longitudinal concentration profiles together with microscopic and BSESEM images revealed specific areas in the glasses. The composition and structure of type B-3 red translucent glass was identified in the Grodziec red glasses. High concentrations of lead, copper and iron determined in external layers of glass samples can be connected with decorative paint layers and drawings. Considerable differences between the composition of healthy bulk glass and the deteriorated surface of glass were also detected and explained by dealkalinisation and manganese browning.

\section{Acknowledgements}

LA-ICP-MS measurements were supported by $\mathrm{Na}$ tional Science Centre of Poland from funds granted within post-doctoral internship based on decision no. DEC-2013/08/S/ST4/00560. SEM-EDX measurements were supported by the National Science Centre of Poland within the project no. 2012/05/E/ HS2/03867.

\section{References}

[1] G. Artioli, Scientific Methods and Cultural Heritage: an introduction to the application of materials science to archaeometry and conservation science, Oxford University Press, New York 2010.

[2] S. Davison, Conservation and Restoration of Glass, Butterworth Heinemann, Oxford 2003.

[3] K. Wedepohl, K. Simon, "The chemical composition of medieval wood ash glass from Central Europe", Chemie der Erde, 70 (2010) 89-97, DOI: 10.1016/j.chemer.2009.12.006.

[4] K. Wedepohl, K. Simon, A. Kronz, “The chemical composition including the Rare Earth Elements of the three major glass types of Europe and the Orient used in late antiquity and the Middle Ages", Chemie der Erde, 71 (2011) 289-296, DOI: 10.1016/j. chemer.2011.04.001.

[5] K. Wedepohl, K. Simon, A. Kronz, "Data on 61 chemical elements for the characterization of three 
major glass compositions in late antiquity and the middle ages", Archaeometry, 53 (2011) 81-102, DOI: 10.1111/j.1475-4754.2010.00536.x.

[6] Ž. Šmit, P. Pelicon, G. Vidmar, B. Zorko, M. Budnar, G. Demortier, B. Gratuze, S. Šturm, M. Nečemer, P. Kump, M. Kos, "Analysis of medieval glass by X-ray spectrometric methods", Nuclear Instruments and Methods in Physics Research B, 161-163 (2000) 718-723, DOI: 10.1016/S0168-583X(99)00947-7.

[7] Ž. Šmit, K. Janssens, E. Bulska, B. Wagner, M. Kos, I. Lazar, "Trace element fingerprinting of façonde-Venice glass", Nuclear Instruments and Methods in Physics Research B, 239 (2005) 94-99, DOI: 10.1016/j.nimb.2005.06.182.

[8] Ž. Šmit, T. Milavec, H. Fajfar, T. Rehren, J. Lankton, B. Gratuze, "Analysis of glass from the post-Roman settlement Tonovcov grad (Slovenia) by PIXE-PIGE and LA-ICP-MS", Nuclear Instruments and Methods in Physics Research B, 311 (2013) 53-59, DOI: 10.1016/j.nimb.2013.06.012.

[9] S. Conte, T. Chinni, R. Arletti, M. Vandini, "Butrint (Albania) between eastern and western Mediterranean glass production: EMPA and LAICP-MS of late antique and early medieval finds", Journal of Archaeological Science, 49 (2014) 6-20, DOI: 10.1016/j.jas.2014.04.014.

[10] B. Velde, "Glass Compositions over Several Millennia in the Western World", in: K. Janssens (Ed.), Modern Methods for Analysing Archaeological and Historical Glass, John Wiley \& Sons Ltd., Chichester 2013, pp. 67-78.

[11] J. Kunicki-Goldfinger, I. Freestone, I. McDonald, J. Hobot, H. Gilderdale-Scott, T. Ayers, “Technology, production and chronology of red window glass in the medieval period - rediscovery of a lost technology", Journal of Archaeological Science, 41 (2014) 89-105, DOI: 10.1016/j.jas.2013.07.029.

[12] E. Gajewska-Prorok, "Stained glass windows from Grodziec. Part I”, Opuscula Musealia, 22 (2014) 73-94, DOI: 10.4467/20843852.OM.14.004.3202.

[13] E. Gajewska-Prorok, "Stained glass windows from Grodziec. Part II”, Opuscula Musealia, 22 (2014) 95-116, DOI: 10.4467/20843852.OM.14.005.3203.

[14] M. Kamińska, P. Karaszkiewicz, "Old and modern methods of stained glass conservation and renovation, using as an example the stained glass depicting St Peter in the collection of the Collegium Maius of the Jagiellonian University in Kraków", Opuscula Musealia, 22 (2014) 123-136, DOI: 10.4467/20843852.OM.14.008.3206.

[15] M. Walczak, M. Kamińska, P. Karaszkiewicz, J. Szczerbiński, M. Szymoński, “The preliminary results on the investigation of historic stained glass panels from Grodziec collection, Poland", Proc. SPIE, 8790 (2013) 87901F, DOI: 10.1117/12.2021197.

[16] M.Walczak, M. Kamińska, J. Sobczyk, M. Płotek, D. Horzela, M. Sylwestrzak, P. Targowski, “The application of non-invasive analytical techniques in the investigation and documentation of medieval stained-glass windows from the Grodziec collection", in: H. Roemich, L. Fair (Eds.), Recent Advances in Glass and Ceramics Conservation, International Council of Museums - Committee for Conservation (ICOM-CC), Paris 2016, pp. 21-30.

[17] K. Jochum, U. Weis, B. Stoll, D. Kuzmin, Q. Yang, I. Raczek, D. Jacob, A. Stracke, K. Birbaum, D. Frick, D. Günther, J. Enzweiler, "Determination of Reference Values for NIST SRM 610-617 Glasses Following ISO Guidelines", Geostandards and Geoanalytical Research, 35 (2011) 397-429, DOI: 10.1111/j.175 1-908X.2011.00120.x.

[18] B. Wagner, A. Nowak, E. Bulska, K. Hametner, D. Günther, "Critical assessment of the elemental composition of Corning archeological reference glasses by LA-ICP-MS", Analytical and Bioanalytical Chemistry, 402 (2012) 1667-1677, DOI: 10.1007/ s00216-011-5597-8.

[19] Y. Liu, Z. Hu, S. Gao, D. Günther, J. Xu, C. Gao, H. Chen, "In situ analysis of major and trace elements of anhydrous minerals by LA-ICP-MS without applying an internal standard", Chemical Geology, 257 (2008) 34-43, DOI: 10.1016/j.chemgeo.2008.08.004.

[20] B. Wagner, A. Nowak, E. Bulska, J. Kunicki-Goldfinger, O. Schalm, K. Janssens, "Complementary analysis of historical glass by scanning electron microscopy with energy dispersive X-ray spectroscopy and laser ablation inductively coupled plasma mass spectrometry", Microchimica Acta, 162 (2008) 415-424, DOI: 10.1007/s00604-007-0835-7.

[21] J. Hormes, A. Roy, G.-L. Bovenkamp, K. Simon, C.-Y. Kim, N. Börste, S. Gai, "Medieval glass from the 
Cathedral in Paderborn: a comparative study using $\mathrm{X}$-ray absorption spectroscopy, X-ray fluorescence, and inductively coupled laser ablation mass spectrometry", Applied Physics A, 111 (2013) 91-97, DOI: 10.1007/s00339-012-7505-2.

[22] M. Gaboardi, M. Humayun, "Elemental fractionation during LA-ICP-MS analysis of silicate glasses: implications for matrix-independent standardization", Journal of Analytical Atomic Spectrometry, 24 (2009) 1188-1197, DOI: 10.1039/B900876D.

[23] E. Vicenzi, S. Eggins, A. Logan, R. Wysoczanski, "Microbeam Characterization of Corning Archeological Reference Glasses: New Additions to the Smithsonian Microbeam Standard Collection", Journal of Research of the National Institute of Standards and Technology, 107 (2002), 719-727, DOI: 10.6028/ jres.107.058.

[24] L. Dussubieux, P. Robertshaw, M. Glascock, "LAICP-MS analysis of African glass beads: Laboratory inter-comparison with an emphasis on the impact of corrosion on data interpretation", International Journal of Mass Spectrometry, 284 (2009) 152-161, DOI: 10.1016/j.ijms.2008.11.003.

[25] G. Zadora, A. Martyna, D. Ramos, C. Aitken, Statistical Analysis in Forensic Science. Evidential Value of Multivariate Physicochemical Data, Wiley, Chichester 2014.

[26] G. Van der Snickt, S. Legrand, J. Caen, F. Vanmeert, M. Alfeld, K. Janssens, "Chemical imaging of stained-glass windows by means of macro X-ray fluorescence (MA-XRF) scanning", Microchemical Journal, 124 (2016) 615-622, DOI: 10.1016/j.mi croc.2015.10.010.

[27] J. van Elteren, A. Izmer, M. Šala, E. Orsega, V. Šelih, S. Panighello, F. Vanhaecke, "3D laser ablation-ICP-mass spectrometry mapping for the study of surface layer phenomena - a case study for weathered glass", Journal of Analytical Atomic Spectrometry, 28 (2013) 994-1004, DOI: 10.1039/ C3JA30362D. 
